\title{
Estancias pampeanas del siglo XIX. Estrategia empresaria para su funcionamiento: chacras agrí- colas y puestos ganaderos.
}

Andrea Reguera'

\section{La formación de estancias}

Según versa en un artículo publicado en los Anales de la Sociedad Rural Argentina, la aparición de la primera marca de ganado, en el año 1589, inició la tendencia de algunos pobladores a terminar con el salvajismo de las vaquerías $^{2}$ y desear establecerse en los campos, es decir, "estacionarse", hacer "estancia" en un sitio determinado. Estanciero, por lo tanto, designa al que hace y tiene estancia (Gutiérrez,1947:549).

Esa primera estancia, según Gutiérrez, se llamó "trinchera" o "caramanchel". Y consistía en un cuadrilátero de tierra (otorgado en donación, composición o merced por el Rey), rodeado por un foso abierto para evitar la entrada de los indios en ataque. En el interior se levantaba un primitivo rancho de paja y cuero, como población. La tarea era la de formar rodeos de ganado vacuno con el fin de explotar la carne, el cuero, la grasa y el sebo con destino a los saladeros y abastos de las ciudades. Para ello, se debía contratar a un grupo de hombres para que saliera a buscar el ganado por los confinés de la estancia.

Tanto la palabra "estancia" como "estanciero", según Juan Carlos Garavaglia (1993:184), se fueron cargando de distintos significados según el tiempo y el lugar, aunque siempre estuvieron vinculados a las unidades $y$ actividades pro-

1-IEHS - UNCBA -

2-Vaquería es la acción de cazar ganado cimarrón. 
ductivas de tipo pastoril ${ }^{3}$.

En nuestro país, la palabra "estancia" pasó a designar a aquél establecimiento basado en una "abundante cantidad de tierra, grandes rebaños de ganado, pocos brazos y baja inversión en activos fijos" (H.Sábato, 1989:130). Esto llevó a identificar a los "estancieros" con los "criadores". Pero, según lo pone de relieve Juan Carlos Garavaglia (1987 y 1993) al analizar las categorías ocupacionales de los censos coloniales correspondientes a 1789 (Areco Arriba) y 1815 (San Isidro), bajo la categoría de "estancieros" también se englobaba a propietarios, arrendatarios, ocupantes de tierras realengas o de dueños desconocidos y agregados en tierras de vecinos.

La otra palabra que aparece teniendo prácticamente la misma connotación es la de "hacendado". Y si bien para el resto de América Latina (en especial México y el mundo andino), la palabra "hacienda" designa a las grandes unidades de producción, propiedad de hombres ricos y poderosos, en la región pampeana designaba al ganado mayor y menor.

También es necesario recalcar que, para algunos de estos historiadores, la estancia no sería la unidad de producción preponderante en la campaña colonial rioplatense. Pues además de las estancias ganaderas, existía un sinnúmero de chacras agrícolas, productoras de cereales para el abasto del mercado urbano (Garavaglia, 1989:565) ${ }^{4}$. Esto no impedía que las estancias ejercieran algún tipo de agricultura (con chacras incorporadas a su hinterland productivo) y que las chacras, a su vez, también tuvieran sus animales. $Y$ que ambas, incluso, pudieran combinar la producción fruto-hortícola.

Esta realidad que muestran los censos, las alcabalas y los diezmos para el período colonial, permiten hablar de un gran sector "campesino" compuesto por pastores y labradores superior al de los "estancieros". Sus características es que no son propietarios de la tierra, hacen uso de la fuerza de trabajo familiar y poseen una cierta capacidad de acumulación. La preponderancia de este sector hace dudar a Garavaglia (1994:117) sobre el dominio de las estancias en el sentido de ser la mayoría de los establecimientos productivos de la campaña, englobar a la mayor parte de la población rural y ser el origen de la mayor parte del producto agrario.

Pero para 1820, la relación empieza a invertirse. Según Halperín Donghi

3-Por ejemplo, en México y Mesoamérica designaba a los sitios del ganado mayor y menor; en las Antillas a las casas de campo; y en el mundo andino a las pequeñas aldeas cercanas a los ganados (Garavaglia, 1993:184).

4-Para analizar la magnitud de la producción triguera en el periodo colonial, consúltense los trabajos de J.Gelman y J.C.Garavaglia que se apuntan en la bibliografia. 
(1992:11), al comenzar en ese año a estructurarse la economía agroexportadora, que alcanzará su punto más alto en 1928, la estancia no sólo se convertirá en la proveedora de la mayor parte de la producción agraria, sino que será "el crisol en la cual se forjaría la cultura política nacional".

Pero de esta primera mitad del siglo XIX, poco es lo que se sabe respecto a esta inversión de la relación entre las unidades de producción y los sectores productivos marcados por Garavaglia y el nuevo poder que empiezan a tener las estancias. Para Halperín es fácil ubicar a los terratenientes en la pampa argentina, pero a "los campesinos no se los encontrará en ninguna parte" (1992:13). Esto se debe a que nuestra historiografía adolece de una gran falta de trabajos para ese espacio temporal. Falta que, afortunadamente, está comenzando a subsanarse con el desarrollo de nuevas investigaciones pero que aún no han presentado resultados concretos.

Ya hacia 1850, según H. Sábato (1989:130), la estancia había conquistado definitivamente el espacio rural. Y su organización se había hecho mucho más compleja, pues junto a la explotación del vacuno ahora se desarrollará la producción del ovino y de una manera más intensiva. Esta nueva estancia va a requerir una importante inversión en activos fijos consistente en alambrados, corrales, galpones para la esquila, aguadas, instalaciones para baños, etc.. Y la organización se complejizará más aún cuando se introduzca la práctica de la agricultura, tanto subsidiaria de la ganadería como comercial, al interior de las estancias.

A esta altura, la palabra estancia comenzará a tener una acepción similar a la que señaláramos páginas arriba para las haciendas latinoamericanas, como sinónimo de riqueza y poder. El incremento de la demanda de los productos ganaderos, el alza de los precios de dichos productos y la disponibilidad de nuevas tierras, consolidarán la especialización productiva de la Argentina y a las estancias como la unidad base para esa expansión.

Según el Código Rural de 1894, estancia "es aquél establecimiento cuyo único y principal objetivo es la cría de ganado vacuno, yeguarizo y lanar" (Daireaux;1887:409). Pero este criterio meramente productivo utilizado para definir lo que es una estancia no es suficiente para aprehenderla en toda su complejidad. Es necesario tomar en cuenta a la estancia como una unidad de producción principalmente agrícola - ganadera con orientación al mercado - lo cual no excluye que parte de su producción se destine al autoconsumo -, y caracterizada por la propiedad privada de la tierra, un número relativamente fijo de trabajadores permanentes y empleo ocasional y estacional de trabajadores temporarios. Esta unidad económica y social compleja es definida por 
el conjunto de relaciones sociales que se crean a partir de los diferentes sectores productivos y de las diferentes formas de trabajo empleados.

La medida básica sobre la que se fundaba una estancia era la llamada "suerte de estancia", de media legua de frente por legua y media de fondo, totalizando una superficie de tres cuarto de legua cuadrada (2.025 hectáreas). Esta "suerte de estancia", estaba calculada para alimentar con pasto natural de 800 a 1.000 cabezas de ganado vacuno de cría. Esto daría un promedio de 2 a 2.5 hectáreas por cabeza y mantener a una sola unidad familiar.

Esta era la unidad base, la que en general se toma como medida de las explotaciones medias, pero a partir de ella las extensiones podían variar. La tendencia era a la acumulación y de esa manera encontramos enormes extensiones de miles y miles de hectáreas que podían estar concentradas en una sola extensión o diseminadas en varias dispares.

$Y$ esto se va a multiplicar, pues a medida que aumente la necesidad de nuevas tierras, debido al incremento de la demanda, se producirá el corrimiento de la frontera. Y aquí, el proceso de formación de estancias se realizará, según Hilda Sábato (1989), por el simple mecanismo de amojonar y poblar tierras. Sólo después de un tiempo se reclamaba el derecho de propiedad 5 .

Al no existir ningún tipo fijo de establecimiento, Daireaux (1908:7) opinará que los problemas de organización laboral, comercial y de producción que enfrentaba cualquier explotación eran los mismos para una estancia de 5.000 hectáreas que para una de 20.000 .

Los elementos que tenían mayor importancia en la elección de un campo eran la ubicación, la fertilidad del suelo, la calidad y fuerza de sus pasturas y la existencia de aguadas. De inmediato se procedía a decidir el tipo de explotación que se iba a seguir. Para que una estancia fuera productiva y habitable se requería una determinada inversión de ćapital fijo y variable. La distribución por porcentaje variaría en relación al período y al tipo de actividad a desarrollar. En primer lugar, la inversión en tierra que, de acuerdo al proceso que venimos de describir en las páginas anteriores, experimentó a lo largo del siglo XIX y XX un proceso de valoración creciente. Luego, los ganados y semillas según la orientación productiva. Acto seguido, las construcciones (corrales,

5- El mecanismo consistia en mensurar los distintos terrenos. Para ello, el agrimensor, según lo que determinaran las autoridades correspondientes, procedia a medir y amojonar. Si el terreno estaba vacio, sin denunciantes u ocupantes previos, el terreno se demarcaba por medio de montículos de tierra y pasto o accidentes naturales. Si por el contrario, el terreno atestiguaba ocupantes o propietarios conocidos, se convocaba a los linderos para que hicieran las oposiciones pertinentes y se procedía a su definitiva demarcación. Pero las tareas nunca fueron demasiado fáciles de realizar (en especial cuando existía oposición de linderos o se demarcaba para subdividir terrenos ya mensurados), lo que redundó en una tarea engorrosa y no siempre bien hecha (Carretero,1970). 
galpones, casas para la familia del estanciero, mayordomo y peones), materiales, máquinas e implementos de trabajo. $Y$ finalmente, la mano de obra.

[...], el primer trabajo que incumbe al poblador de una estancia, dice Daireaux (1887:22), es, forzosamente, de construir los techos que le deben abrigar a él, a su familia, a sus peones y también deben prote ger su material y sus animales.

Junto con la edificación se realizaba el cercado de los campos, no sólo para proteger los edificios y sembrados de la invasión de los animales, propios o ajenos, sino para cerrar la estancia y marcar sus divisiones internas. De campos nutridos a pastos naturales se pasa a prados artificiales, los alfalfares. De viejas casas hechas de adobe y paja a casas de material.

La estancia, en cuanto a organización, es una unidad económica-social que está en permanente transformación. Con una gran capacidad de adaptación según el delicado equilibrio surgido de las exigencias de una demanda en permanente cambio y de las bondades de la "madre" naturaleza. Para fines del siglo XIX y principios del XX, vamos a encontrar un modelo de estancia mixta que combinará alternativamente la producción agrícola con la ganadera (cría e invernada).

Pero está claro que lo que diferencia a las explotaciones no es su tamaño sino el control que ejercen sus propietarios sobre la asignación de los diferentes factores de la producción y la información y el conocimiento que tienen sobre el acceso a los medios y el funcionamiento del sistema.

\section{Acumulación e inversión en tierras nuevas}

Es interesante observar el movimiento de concentración y fragmentación que experimentó la propiedad de la tierra. Las primeras adquisiciones, producto de denuncias enfiteúticas y posteriores ventas por parte del Gobierno de la Provincia de Buenos Aires a esos mismos enfiteutas u otros particulares, tenían una extensión de 10 leguas cuadradas promedio cada una. El Partido de Tandil $^{6}$, según el mapa catastral del año 1826 , por ejemplo, quedó dividido en 16 parcelas que correspondían a 16 enfiteutas diferentes. De esos 16 enfiteutas, algunos tenían más de una enfiteusis en algún otro partido de la provincia de

6-"El Fuerte de la Independencia" (Tandil) fue fundado en 1823 por Martín Rodríguez como fuerte de avanzada de la frontera. 
Buenos Aires.

Al agregar los datos correspondientes a los mapas catastrales de los años 1864 y 1890 , los de la Guía Rural del Partido de Tandil del año 1909, los de la Guía de Propietarios Edelberg del año 1923 y los de la Guía de Propietarios de Campo por Cuarteles del Partido de Tandil del año 1928, es posible ver en el cuadro 1 las variaciones experimentadas en el número de las propiedades y de los propietarios a lo largo del período.

Entre 1826 y 1864 la división de la propiedad de la tierra se duplicó. De los 16 propietarios enfiteutas que figuran en el registro de 1826 , uno solo vuelve a encontrarse en el registro de 1864. Esto quiere decir que en el momento en que el Estado inició el traspaso de las tierras públicas a manos privadas se dió un recambio absoluto de propietarios.

En 1864 volvemos a encontrar equiparados el número de propiedades y propietarios. Esto se debe a que se dan 3 casos de propiedades que figuran con dos propietarios y 3 casos de propietarios que figuran con dos propiedades cada uno. Entre 1864 y 1890, la subdivisión de la propiedad se triplicó. Y el número de propietarios se duplicó. De los 35 propietarios que aparecen registrados en 1864, 24 reaparecen en 1890.

En 1890, la propiedad vuelve a triplicarse. $Y$ a partir de ese año seguirá subdividiéndose pero en menor proporción. A su vez, de los 93 propietarios que figuran en el registro de ése año, 39 se repiten en 1909.

Para el año 1909 la Guía Rural del Partido de Tandil nos proporciona el nombre y apellido del propietario, la ubicación de la propiedad por cuartel y su lugar de residencia. De esta manera pudimos saber que las propiedades duplicaron su número y los propietarios prácticamente lo triplicaron.

CUADRO 1: Evolución de la propiedad de la tierra en el Partido de Tandil 1826-1928

\begin{tabular}{|c|c|c|c|c|}
\hline Año & \multicolumn{4}{|c|}{ Cantidad de } \\
\hline & Propiedades & \multicolumn{3}{|c|}{ Propietarios } \\
\hline & & Masculinos & Femeninos & Total: \\
\hline 1826 & 16 & 16 & - & 16 \\
\hline 1864 & 35 & 29 & 6 & 35 \\
\hline 1890 & 114 & 75 & 18 & 93 \\
\hline 1909 & 264 & 175 & 77 & 252 \\
\hline 1923 & 345 & 201 & 108 & 309 \\
\hline 1928 & 342 & 215 & 83 & 298 \\
\hline
\end{tabular}

Fuente: Mapas catastrales de 1826, 1864 y 1890, Guía Rural del Partido de Tandil de 1909, Guia de Propietarios Edelberg de 1923 y Guia de Propietarios de Campo por Cuarteles del Partido de Tandil de 1928. 
Siguiendo con los propietarios, vemos que de los 252 que contabilizamos en 1909, 126 se repiten en 1923. Y de los 309 propietarios que figuran en 1923, 196 se repiten en 1928. Algo a tener en cuenta es que en el registro de 1909 aparecen 27 propietarios que no figuran en la guía de 1923 pero que sí figuran en la de 1928. Esto quizás se deba a cambios en la forma de registrar a los titulares de las propiedades.

Lo que se evidencia es, especialmente a partir de 1890, una creciente subdivisión en la propiedad de la tierra consecuencia de continuas particiones de herencias y ventas sucesivas. Las variaciones son bastante heterogéneas. Lo que es innegable es el proceso de fragmentación continua. Cómo de una propiedad nacen nuevas propiedades. El problema es que no podemos ver qué porcentaje correspondió a partición por herencia o a partición por venta, pues eso implicaría un análisis del catastro que excedería los límites de nuestro trabajo. De todas maneras, es posible extraer algunos datos. La Guía Rural de 1909 al proporcionar información sobre el nombre de los actuales y anteriores propietarios nos permite saber que 181 propiedades se transmitieron por venta, 76 por herencia y 8 quedaron en manos de los mismos propietarios.

Otro problema que se nos presenta es ver la conformación de las propiedades por cantidad de hectáreas. El Mapa de 1826 y las Guías Rurales de 1923 y 1928 aportan el dato de la cantidad de hectáreas por propiedad. Para ello, las hemos agrupado en el cuadro 2 según una escala de magnitud en base a las Guías mencionadas. No hemos incluído los datos del Mapa de 1826 por no poder adecuarlo a la escala presentada.

Entre 1923 y 1928, el proceso de fragmentación siguió su curso. Si se hace una comparación de escala por escala, se observarán algunas pequeñas variaciones. Hasta 1923 las propiedades de hasta 100 hectáreas no habían hecho su aparición. En 1928 comenzaron a constituir una minoría. La gran concentración se produce entre las propiedades pequeñas y medianas (de 100 a 2500 has.). Son pocas las grandes estancias de más de 5000 has.. Sin embargo, éstas son, en proporción, las que ocupan la mayor cantidad de superficie. También se da el caso de que un propietario tenga más de una propiedad y éstas generalmente están ubicadas en diferentes cuarteles del partido, en tanto que cuando se trata de una subdivisión por herencia, las distintas propiedades de los miembros de las familias quedan una al lado de las otras.

Como corolario, diremos que la trayectoria ascendente que algunas importantes familias propietarias pudieron tener, evolucionó según el dinamismo de los individuos, la singularidad de las situaciones familiares y las condiciones económicas del momento. De donde provienen los bienes? Del circuito fami- 
liar que reposa sobre la herencia y del mercado de tierras que supone disponibilidad monetaria.

CUADRO 2: Propiedades del Partido de Tandil en 1923 y 1928 por número y superficie ocupada en hectáreas

\begin{tabular}{|c|c|c|c|c|}
\hline \multirow{2}{*}{$\begin{array}{c}\text { Escala de } \\
\text { Magnitud }\end{array}$} & \multicolumn{2}{|c|}{$\mathbf{1 9 2 3}$} & \multicolumn{2}{c|}{$\mathbf{1 9 2 8}$} \\
\cline { 2 - 5 } & \multicolumn{2}{|c|}{$\begin{array}{c}\text { Numero de superficie } \\
\text { Propiedades Ocupada }\end{array}$} & \multicolumn{2}{c|}{$\begin{array}{c}\text { Número de superficie } \\
\text { Propiedades Ocupada }\end{array}$} \\
\hline $0-10$ & - & - & - & - \\
\hline $11-100$ & - & - & 11 & 723 \\
\hline $101-500$ & 132 & 41.245 & 125 & 33.838 \\
\hline $501-2500$ & 172 & 190.153 & 159 & 193.199 \\
\hline $2501-5000$ & 23 & 73.896 & 30 & 101.488 \\
\hline 5000 yás & 18 & 134.502 & 17 & 136.925 \\
\hline Totales: & $\mathbf{3 4 5}$ & $\mathbf{4 3 9 . 7 9 6}$ & $\mathbf{3 4 2}$ & $\mathbf{4 6 6 . 1 7 3}$ \\
\hline
\end{tabular}

Fuente: Guía de Propietarios Edelberg de 1923 y Guía de Propietarios de Campo por Cuarteles del Partido de Tandil de 1928.

\section{Formación de patrimonios}

En el espacio de la región pampeana es posible ver diversos casos de formación de patrimonios territoriales. Uno de los más importantes fue el de Ramón Santamarina ${ }^{7}$.

Cuando Ramón Santamarina llegó a Tandil en 1844, ya se habían formado las primeras y grandes estancias de la zona. Si bien su primera inserción laboral fue trabajar como peón en la estancia de la familia Gómez, será a través del comercio con sus carretas y el acceso al crédito que logrará acumular un importante capital y así consolidar su fortuna con la compra de grandes extensiones de tierra. Durante largo tiempo, Santamarina realizó con sus carretas continuos viajes a la capital trayendo toda clase de mercaderías para abastecer los almacenes de campaña y proveer parte de las fuerzas defensoras de la zona a cargo del Coronel B. Machado. Por estas diligencias, según E. Delpech (1944:141), recibió en pago documentos a cargo del gobierno de la provincia

7-Ramón Santamarina llegó al Río de la Plata, proveniente de Galicia, en 1840 cuando tenía 13 años de edad, engrosando así el grupo de los llamados "inmigrantes tempranos". Sin cartas de recomendación, sin parientes ni amigos, sin previo conocimiento de estas tierras, realizó, a su llegada a Buenos Aires, diversos trabajos hasta conseguir un empleo de boyero en una tropa de carretas que lo trajo a Tandil en 1844. Para un conocimiento más acabado de su biografia, consúltese A.Reguera: "Estancias et entrepreneurs dans le cadre du développement de l'ecosysteme agraire de la région de la pampa (1880-1930). Etude de cas". Tesis de Doctorado, Paris, EHESS, 1997. 
de Buenos Aires que luego transformaría en tierras a las que fue poblando de hacienda e instalando sus propios almacenes de campaña. Su patrimonio territorial llegó a contar 33 estancias diseminadas en diversos partidos de la provincia de Buenos Aires sumando un total de 281.727 hectáreas. De este total, 24.288 has. correspondieron al Partido de Tandil donde concentró sus estancias más importantes: Dos Hermanos de 10.367 has., Los Angeles de 11.555 has. y La Claudina de 2.366 has. $^{8}$

Su patrimonio comenzó con la adquisición de solares en el ejido urbano y chacras y quintas en las afueras de la ciudad. En 1853, Santamarina fue favorecido por una política distributiva de la Municipalidad de Tandil que distribuyó gran número de solares y suertes de chacras sujetas al pago de un impuesto y a la obligación de poblarlas (levantar una vivienda y/o cultivar el terreno) en un término perentorio. Así adquirió un total de 26 terrenos entre 1864 y 1889 en el ejido urbano de Tandil -de este total de 26, 24 corresponden a solares adquiridos al gobierno y sólo 2 a particulares-, 8 quintas (46 has.) compradas a la Municipalidad de Tandil entre 1871 y 1887 y 22 chacras (532 has.) adquiridas entre 1875 y 1902 a particulares.

Entre 1864 y 1902, Santamarina se beneficia en principio de la donación de tierras hecha por el Estado e inmediatamente observa una política constante de inversión en inmuebles y pequeñas extensiones. Remarquemos también que, hacia 1869, figura en el Registro de la Contribución Directa como uno de los propietarios más importantes.

También hay otros bienes que es necesario mencionar: una casa-quinta en San Fernando (Provincia de Buenos Aires), en el paraje llamado Punta Chica (1903); una propiedad rural en el Partido de San Vicente (Provincia de Buenos

8- La estancia Dos Hermanos le correspondió a Ramón Santamarina por compras que hizo en varias fracciones: una fracción de 1.575 has. fue adquirida a Facundo Piñero en 1863 (Mensura $N^{\circ} 29$-Tandii), otra fracción de 2.699 has. a Ramón Oliden en 1872 (Mensura $N^{\circ}$ 59-Tandil), otra fracción de 2.057 has. al Superior Gobierno de la Provincia de Buenos Aires en 1875 (Mensura $\mathrm{N}^{\circ}$ 30-Tandil), otra fracción de una legua y media cuadrada a Enrique Thompson en 1876 (Mensura $N^{\circ} 59$ ), otra a la testamentaria de Justo Silva y Magdalena Gómez de Silva en 1884 y otra de 1.113 has. a Rafael Benedicto Luciano López y Gómez en 1899 (Mensura No 128-Tandil). La estancia Los Angeles la tenía Juan N. Fernández en enfiteusis desde 1827. En 1834, Juan N. Fernández transfiere esta enfiteusis a Manuel Zenón Duval, quien en 1836 compra el terreno al Superior Gobierno de la Provincia de Buenos Aires y en 1869 su testamentaría se la vende a Ramón Santamarina (Mensura $N^{\circ} 6$-Tandil). La estancia La Claudina estaba compuesta por tres fracciones que formaban los potreros "La Pompeya" de 800 has., "Pilar" de 1.003 has. y "San Ramón" de 563 has.. Esta propiedad fue adquirida el 26 de diciembre de 1903. La propiedad también incluye las chacras anexas al campo y demarcadas con los $\mathrm{N}^{\circ} 231,232,244$ y 245 y el lote de sierra designado con el $N^{\circ} 1$. Estas fueron adquiridas el 19 de marzo de 1904 con un total de 295 has. (Catálogo General de Mensuras, Archivo Histórico, Dirección de Geodesia de la Provincia de Buenos Aires). 
Aires) de 765 has. (1886); un terreno en el Partido de Almirante Brown (Provincia de Buenos Aires); 6 chacras en el ejido de Tres Arroyos que suman una extensión total de 252 has. y una treintena de propiedades en la ciudad de Buenos Aires.

Respecto de las inversiones urbanas, es necesario distinguir aquellas de la ciudad de Tandil de aquellas de la ciudad de Buenos Aires. Obviamente, las primeras inversiones corresponden a la ciudad de Tandil. La primera adquisición, correspondiente a la casa familiar, data de 1864. Las compras continuaron hasta 1889, nueve años después de la instalación de la familia en la ciudad de Buenos Aires. La primera adquisición efectuada en ésa ciudad data de 1878 , dos años antes de instalarse en dicha ciudad. Es obvio que las inversiones urbanas tuvieron que ver con un interés mercantil para la obtención de renta.

En cuanto a las inversiones rurales, estas fueron efectuadas en diferentes partidos de la provincia de Buenos Aires. Si comparamos la información extraída del Juicio de Sucesión con aquella proporcionada por los Duplicados de Mensuras, podemos comprobar que todas las tierras adquiridas por Ramón Santamarina por sí o a través de la Sociedad Comercial "Santamarina é hijos" en diversos partidos de la provincia de Buenos Aires, fueron por compras hechas al Superior Gobierno de la Provincia de Buenos Aires y/o a particulares. Se trata de extensiones que reconocían un movimiento inmobiliario previo, fruto de subdivisiones de antiguas enfiteusis o de antiguas propiedades.

La variedad de situaciones que presentan las transacciones de tierras es bastante amplia. Santamarina compra tierras en un momento en que el estado transfiere tierras de dominio público al privado pero también en un momento en que esa misma tierra experimenta continuos traspasos entre particulares. Ya sea por transferencia de derechos de enfiteusis, compra directa, testamentarías o litigios, él reúne un total de 281.727 has. de las mejores tierras de la pampa. La gran concentración de tierras se produce en la zona del sudeste pampeano. Esta concentración es posible constatarla no sólo por la cantidad de establecimientos adquiridos, sino también por la cantidad de hectáreas que concentró por partido (véase cuadro 3).

Las adquisiciones que Ramón Santamarina efectuó hasta 1890, aproximadamente, corresponden a las registradas bajo su propio nombre. Luego, las adquisiciones que se realizaron con posterioridad se hicieron a nombre de la sociedad comercial Santamarina é hijos. En este período, cabe observar una importante inversión en tierras que se efectuó en los primeros años de la década de 1870. Luego, la intensidad de las compras disminuyó hasta retomar un nuevo ritmo que volvió a decaer después del fallecimiento del fundador de la 
empresa. El pico más alto de ése nuevo ritmo se registró en 1900; y esto sin contar las adquisiciones efectuadas en otras provincias, como por ejemplo Santiago del Estero, con lo que la contabilisación de las adquisiciones llegó a sobrepasar el total de 100.000 hectáreas adquiridas en un sólo año9.

En cuanto a las compras de tierras efectuadas en otras provincias argentinas, los datos son los siguientes. En la Provincia de Río Negro adquirió 2.024 has. y en Santiago del Estero llegó a tener 50 leguas de campo de 1.880 has. (94.000 has.) cada una a una cotización de $\$ 2.40$ la hectárea.

CUADRO 3: Cantidad de hectáreas y de estancias de Ramón Santamarina en la Provincia de Buenos Aires, por partido

\begin{tabular}{|l|c|c|}
\hline \multicolumn{1}{|c|}{ Partido } & Hectareas & Estancias \\
\hline Tres Arroyos & 49.102 & 7 \\
\hline Laprida & 48.597 & 3 \\
\hline Necochea & 35.118 & 3 \\
\hline Coronel Dorrego & 33.280 & 3 \\
\hline Juárez & 27.881 & 4 \\
\hline Tandil & $\mathbf{2 4 . 2 8 8}$ & 3 \\
\hline Pehuajó & 19.204 & 3 \\
\hline Coronel Vidal & 17.492 & 1 \\
\hline Lamadrid & 8.100 & 1 \\
\hline Magdalena & 8.099 & 1 \\
\hline Patagones & 2.024 & 1 \\
\hline Carmen de Areco & 4.493 & 1 \\
\hline Bahía Blanca & 4.048 & 2 \\
\hline Total & 281.727 & 33 \\
\hline
\end{tabular}

Fuente: Expediente 2786 correspondiente a la Sucesión de Ramón Santamarina (Archivo Ramón Santamarina, en adelante ARS)

Como se puede observar, Ramón Santamarina comenzó a adquirir tierras después de 23 años de su llegada a la Argentina, entre tanto si pudiéramos considerar como fiable la fecha de su primera compra de tierra, la de la estancia "El Cristiano" (de la cual no poseemos documentación), podríamos decir que,

9-Para mayor detalle sobre la formación del patrimionio de la familia Santamarina, consúltese A.Reguera: "Familia, formación de patrimonios y transmisión de la tierra en Tandil (1840-1930)" en: J.C.Garavaglia, J.Gelman y B.Zeberio (comps.): Expansión capital ista y transformaciones regionales. Relaciones sociales y empresas agrarias en la Argentina del siglo XIX, Buenos Aires, IEHS-La Colmena, 1999. 
hasta su muerte en 1904, observó una política permanente de inversión en tierras, continuada por sus hijos a través de la sociedad comercial Santamarina é hijos $^{10}$. Sus hijos donaron luego muchas de las estancias que habían recibido en herencia para la formación de centros de población.

Aunque el mayor porcentaje del capital fue invertido en bienes raíces, ello no impidió que otros campos de inversión como acciones, títulos, préstamos y bienes urbanos hayan sido también importantes para la reproducción del capital. Pero fue la formación de un gran patrimonio territorial el mayor suceso de Santamarina.

\section{Estancias en funcionamiento}

Si bien la forma de organizar la producción varía de una explotación a otra, es posible observar una cierta homogeneidad organizacional en cuanto a la disposición de los espacios afectados a utilizaciones diferentes.

La práctica consistía en combinar en tierra propia y/o arrendada una producción mixta orientada al mercado. Un porcentaje era reservado al autoconsumo (huerta, porqueriza, lechería, aves, árboles frutales), pero un porcentaje mayor de la producción era destinado al mercado. Se trataba de utilizar al máximo los recursos productivos y de disminuir las pérdidas -en particular aquellas producidas por riesgos de producción (sequías, heladas, inundaciones) y riesgos de mercado. Es a esto que respondía la dispersión de parcelas, puestos ganaderos y chacras agrícolas divididos en potreros alambrados, obteniendo, mediante la diversificación, espacial y productiva, ingresos más elevados.

El tamaño de cada una de estas secciones (puestos-chacras-potreros) podía variar en función de la asignación que cada estanciero decidiera de sus recursos productivos. Esta distribución, a su vez, estaba determinada por la demanda del mercado y las condiciones naturales del suelo.

Este es el esquema de organización que corresponde a una unidad de producción. Pero, la organización devenía cada vez más compleja cuando a esa

10- La firma comercial fue fundada en 1890 bajo el nombre de Santamarina y Cía. y atendía el ramo bancario, comisiones y consignaciones de frutos del país, explotaciones industriales y rurales, explotación de agencias, casas de comercio y comanditas, compra y venta de bienes raíces, administración y arrendamiento de propiedades en todo el pais (en especial en las provincias de Córdoba, Buenos Aires, Santiago del Estero, Santa Fe y territorios nacionales), préstamos de dinero con garantía hipotecaria, participación en sociedades de cualquier clase y toda operación por cuenta propia y ajena. El 15 de noviembre de 1902 se firmó un "Acta de Familia" por la cual se constituía la Sociedad Santamarina é hijos en Comandita por Acciones (Reguera, 1999a). 
unidad se le agregaban otras unidades, tanto en propiedad como en arrendamiento" .

Toda organización tiende a la centralización, en ausencia de fuerzas que ejerzan abiertamente en sentido contrario. En el caso de Ramón Santamarina, por ejemplo, la administración central estaba instalada en la estancia Dos Hermanos, desde donde era controlado todo el movimiento productivo, comercial y laboral de puestos y chacras de la estancia. Asímismo, los libros reflejan las relaciones productivas y comerciales con otras estancias pertenecientes al mismo propietario, como Los Angeles en Tandil, Dos Anas en Tres Arroyos y San Ramón y San José de la Tinta en Juárez, o arrendadas como Campo Montiel, Campo Caparrós, Campo de Piñeiro en Tandil. Esta administración, a su vez, dependía de la Casa Central que funcionaba en Buenos Aires. José Santamarina, hijo de Ramón Santamarina, a cargo de la administración de las estancias de la familia, realizaba continuos viajes de control y supervisión de una estancia a otra y de estas a Buenos Aires para llevar información y recibir directivas. Entretanto, el control del trabajo efectivo era asegurado por el mayordomo, quien registraba todo el movimiento de las estancias en los libros diarios y en los libros de trabajos. La organización de las tareas era efectuada por los capataces y las tareas mismas realizadas por los peones, chacareros $y$ puesteros.

Si bien todos los cuadros en que estaban subdivididas las estancias poseían la misma orientación productiva, la producción agrícola-ganadera, es posible reconocer algunas diferencias de especialización. Es desde el casco de la estancia Dos Hermanos, desde donde se tomaban las decisiones y se distribuían los trabajos y recibían los frutos.

Los puestos estaban orientados a la producción ganadera, vacuna y ovina, con predominio del lanar e invernada de carneros y, algunos, incluían chacras con producción de forrajeras y cereales. Las chacras, a su vez, estaban orientadas a la producción agrícola. Algunos de sus cuadros tenían montes de sauce con producción de leña para el calentamiento de las marcas para las yerras, alimento de las máquinas de esquilar, cocina de los peones y casa de familia $y$ postes para alambrados. $Y$ otros cuadros tenían producción de quinta para toda la estancia.

El intercambio existente entre puestos y chacras era intensísimo. Regulado por el mayordomo, este intercambio tenía por objeto hacer frente a las necesidades productivas del establecimiento y las demandas del mercado.

11- Para este tema consúltese A. Reguera: "Riesgo y saber. Control y organización productiva en las estancias pampeanas (1880-1930)" en: Anuario IEHS, Nº 14 (1999b), IEHS, Tandil. 
La diversidad de acceso al ejercicio de la actividad productiva estuvo reglada por acuerdos contractuales. Lamentablemente no hemos podido encontrar, para fines del siglo XIX, ningún contrato escrito. Esto puede explicarse por la costumbre de la época que imponía contratos orales más que escritos. Notemos, en este sentido, las observaciones hechas en 1867 por el estanciero Miguel Cuevas a propósito del artículo 241 del Código Rural:

¿La palabra contrato que este articulo menciona, debe entenderse por escribir lo que se pacta?

Creemos que sí.

¿Y cuando la obra o trabajo es tan pequeño que no merece la pena c'e escribir el convenio, cuando no saben hacerlo los interesados y ni tampoco hay en mucha distancia quien lo sepa hacer, o quizá faltan los medios para ello?

Todos estos inconvenientes y tal vez otros más tiene esto en la práctica, y cumplimos al indicarlos con el deber que nos hemos impuesto, para que se trate de hacer una enmienda en esta disposición" ${ }^{\prime 2}$.

Esto muestra el desconocimiento frecuente, de parte de aquellos que legislan, de las prácticas vigentes en el campo. Es por ello que la utilización de ciertos tipos de contratos podía depender del hecho de que algunos estuvieran fundados ya sea en la confianza ya sea en una relación de fuerzas. Hacia comienzos del siglo XX la situación comienza a cambiar. Las dos primeras décadas del siglo son particularmente interesantes ya que este fue el momento donde se hizo sentir la necesidad de una legislación agraria que, finalmente, lograda después de una serie de conflictos rurales exigió que se regularan las contradicciones sociales existentes entre las partes $^{13}$.

\section{Chacras agrícolas}

En el balance contable del año 1890, aparecen asentadas un total de trece chacras destinadas a la producción agrícola de las cuales se analizarán sólo

12-Observaciones al Código Rural por Miguel Cuevas escritas con el objeto de ser presentadas en la reunión que se va a tener en el Juzgado de Paz de Arenales el 09/07/1867 con el objeto de discutir las enmiendas que sean presentadas por los Señores de la reunión y proponer al gobierno las que sean aceptadas por la mayoría de dicha reunión (Archivo Privado Miguel Cuevas).

13- El tema de la contratación agraria ha sido objeto de análisis en A.Reguera: "Arrendamientos y formas de acceso a la producción en el sur bonaerense: el caso de una estancia del Partido de Necochea, primera mitad del siglo XX"en: R.Mandrini y A.Reguera (comps.): Huellas en la tierra, Tandil, IEHS, 1993. 
siete que son sobre las cuales se posee información completa. Este balance muestra las liquidaciones de cuentas de las chacras -que representan al dueño de las mismas, esto es a Santamarina- y de los chacareros con especificación de las utilidades percibidas y las existencias según inventario.

Estas chacras fueron entregadas a agricultores bajo el régimen de medianería con participación a medias en las ganancias. El propietario, como socio capitalista, facilitaba la tierra y todo lo necesario para el trabajo agrícola. Este capital era debidamente cargado a cuenta en el debe del chacarero. El chacarero, como socio trabajador, aportaba su trabajo y percibía la mitad de las ganancias excluídas e incluídas en inventario (Cuadro 4).

CUADRO 4: Utilidades de las chacras de Ramón Santamarina en 1889/1890Valores en pesos)

\begin{tabular}{|c|c|c|c|c|c|c|}
\hline \multirow[t]{3}{*}{ Chacra } & \multicolumn{3}{|c|}{$\begin{array}{c}\text { Chacra } \\
\text { Existencias según Inventario }\end{array}$} & \multirow{3}{*}{$\begin{array}{c}\text { Chacarero } \\
\text { Ganancia e } \\
\text { Inventario }\end{array}$} & \multirow{3}{*}{$\begin{array}{c}\begin{array}{c}\text { Estancia } \\
\text { Ganancias y } \\
\text { Pérdidas }\end{array} \\
\text { C (50\%) }\end{array}$} & \multirow{3}{*}{$\begin{array}{c}\begin{array}{c}\text { Chacarero } \\
\text { Ganancia } \\
\text { Neta }\end{array} \\
\text { C-B }\end{array}$} \\
\hline & \multirow[t]{2}{*}{1889} & \multicolumn{2}{|c|}{1890} & & & \\
\hline & & $\mathbf{A}$ & B & & & \\
\hline 25 de marzo & 5924.82 & 2566.88 & 1283.44 & 8154.78 & 4077.39 & 2793.95 \\
\hline 31 de enero & 2295.99 & 3733.44 & 1866.72 & 5455.24 & 2727.62 & 860.90 \\
\hline Germania & 475.83 & 7459.57 & 2072.59 & 4145.18 & 2072.59 & Incluída \\
\hline Retiro & 575.34 & 2876.69 & 1238.35 & 3311.05 & 1655.52 & 417.18 \\
\hline Destino & - & 7267.29 & 1627.59 & 3255.18 & 1627.59 & Incluída \\
\hline Santa Rosa & 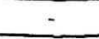 & 975.51 & 487.76 & 2400.09 & 1200.04 & 712.28 \\
\hline La Unión & 2002.59 & 2418.40 & 459.84 & 919.69 & 459.84 & Inclufda \\
\hline
\end{tabular}

Fuente: ARS

Nota: La ganancia neta (C-B) del chacarero esta contenida en las ganancias según inventario $B$.

Las chacras muestran una importante inversión en muebles, maquinarias, carros y arados. Los valores indicados en los inventarios son presentados en el cuadro 5. Exceptuando las existencias de trigos, que son las más importantes, el rubro que evidencia mayor inversión de capital es el de maquinarias.

Si bien la máquina ejecuta más completamente el trabajo y acrecienta su rendimiento, su contrapartida es la elevada inversión de capital que se requiere para su adquisición y los altos costos de mantenimiento para su conservación, aunque tampoco se convierte en algo imposible de alcanzar. La forma de hacerlo era a través de la Casa Central. La adquisición de las máquinas aparece en el Haber de la Cuenta Muebles, Maquinarias y Utiles de la estancia y cargadas en el Debe correspondiente de cada chacra. 
CUADRO 5: Valores en las chacras de Santamarina de Bienes Muebles, Máquinas, Carros y Arados, Trigo y Avena según Inventario de 1890 (Valores en Pesos)

\begin{tabular}{|c|c|r|r|r|r|r|}
\hline Chacra & Muebles & Maquinas & Carros y Arados & \multicolumn{1}{c|}{ Trigo } & \multicolumn{1}{c|}{ Avena } & Total \\
\hline 25 de marzo & 146.03 & 1100.80 & 449.04 & 23085.00 & 72 & 24852.87 \\
\hline 31 de enero & 329.28 & 450.00 & 254.16 & 2700.00 & - & 3733.44 \\
\hline Germania & 344.03 & 1213.34 & 355.20 & 5527.00 & - & 7439.57 \\
\hline Retiro & 354.37 & 756.00 & 108.32 & 1050.00 & 208 & 2476.69 \\
\hline Destino & 16.16 & 366.67 & 96.96 & 6787.50 & - & 7267.29 \\
\hline Santa Rosa & 74.76 & 366.67 & 84.08 & 450.00 & & 975.51 \\
\hline La Unión & 217.94 & 630.00 & 212.96 & 1357.50 & & - \\
\hline Total: & $\mathbf{1 4 8 2 . 5 7}$ & $\mathbf{4 8 8 3 . 4 8}$ & $\mathbf{1 5 6 0 . 7 2}$ & $\mathbf{4 0 9 5 7 . 0 0}$ & $\mathbf{2 8 0}$ & 2418.40 \\
\hline
\end{tabular}

Fuente: ARS

De esta manera, en 1890, la chacra 25 de marzo adquirió dos segadoras a $\$ 580$ cada una, Germania tres máquinas Mc Cormick a $\$ 567$ cada una y una sembradora a $\$ 119$, Destino una máquina a $\$ 550$, Retiro dos segadoras a $\$ 567$, Santa Rosa una máquina Reliance a $\$ 550$ y La Unión una segadora Wood a $\$ 570$. En total existían una sembradora y diez segadoras. Por su parte, la Casa Central había adquirido una máquina trilladora a $\$ 10.292 .85$. Como se podrá apreciar la diferencia de precios entre la trilladora y las otras máquinas es importante. Si relacionamos las utilidades percibidas por los chacareros veremos que es posible que pudieran adquirir arados de $\$ 12, \$ 25, \$ 30, \$ 45$ o $\$ 60$, sembradoras de $\$ 119$ y segadoras de $\$ 550$ y $\$ 570$ para armar su propio parque mecánico. Si comparamos estos precios con el de la trilladora, veremos que su valor equivalía prácticamente al total de las utilidades percibidas por el grupo de los siete chacareros que presentamos en el cuadro 4. Su utilización esta reservada para cantidades superiores de cereal. La relación de precios respecto al de las otras máquinas es de 1 a 20.

La presentación parece ser un poco artificial. En efecto, las máquinas son adaptadas a las dimensiones de una chacra, salvo la máquina de sembrar, en tanto que la trilladora no se justifica más que para la escala de la estancia (esto puede aplicarse al caso europeo en donde las explotaciones si bien tienen sus arados y sus segadoras no tienen más que una trilladora que se desplaza entre las diferentes explotaciones entre los meses de julio, agosto y septiembre). Resta lo mismo para las chacras que, al no tener todas el mismo material, deben por lo tanto prestarse las máquinas las unas a las otras.

Las otras chacras también poseían más maquinaria. La chacra 31 de enero, por ejemplo, poseía dos máquinas Guerrero, la chacra Santa Rosa un arado completo con aperos y dos arados Guerrero y la chacra La Unión 4 arados A, 
un arado usado y una máquina Guerrero. Para hacer uso de estas máquinas era necesario contar con los implementos y suministros necesarios.

También era común acceder al uso de carros de transporte y máquinas alquilándolas a otros chacareros o al propietario. Se trata de intercambio de servicios tarifados por el propietario y que figuraban en los haberes y en los debe de cada chacra. Estos gastos junto a los de la mano de obra en la época de cosecha estan consignados en el cuadro 6

CUADRO 6: Gastos de la cosecha de trigo en siete chacras de Ramón Santamarina en 1890

\begin{tabular}{|c|c|c|c|c|c|c|}
\hline \multirow[t]{3}{*}{ Chacra } & \multicolumn{4}{|c|}{ Alquiler de } & \multirow{3}{*}{$\begin{array}{c}\begin{array}{c}\text { Jornales } \\
\text { de la } \\
\text { Trilladora }\end{array} \\
\text { Pesos } \\
\end{array}$} & \multirow{3}{*}{$\begin{array}{c}\begin{array}{c}\text { Vales de } \\
\text { Peones }\end{array} \\
\text { Pesos } \\
\end{array}$} \\
\hline & \multicolumn{2}{|c|}{ Carros } & \multicolumn{2}{|c|}{ Máquinas } & & \\
\hline & Días & Pesos & Días & Pesos & & \\
\hline 25 de marzo & 254 & 659.00 & 32 & 273.00 & 1420.04 & 4531.33 \\
\hline 31 de enero & 110 & 447.25 & - & - & 1363.75 & 1546.69 \\
\hline Germania & 109 & 439.00 & 14 & 256.50 & 1423.01 & 2271.07 \\
\hline Retiro & 83 & 334.00 & 12 & 162.50 & 660.26 & 1442.84 \\
\hline Destino & 57 & 228.00 & 13 & 225.50 & 404.19 & 942.85 \\
\hline Santa Rosa & 50 & 224.00 & 14 & 191.75 & 698.00 & 738.82 \\
\hline La Unión & 58 & 234.00 & - & - & 648.00 & 2399.52 \\
\hline Total: & & 2565.25 & & 1109.25 & 6617.25 & 13873.12 \\
\hline
\end{tabular}

Fúente: ARS

Nota: Hemos desglosado el item mano de obra en Jornales de la Trilladora y Vales de Peones.

El intercambio entre chacras también abarcaba otros rubros. Por ejemplo leña, cereales y animales.

Aunque las inversiones en maquinaria persigan el objetivo de disminuir costos de trabajo, el rubro de gastos que sigue siendo más alto en la cosecha de cereales es el de la mano de obra. La suma total equivale prácticamente a la mitad del total de gastos del conjunto de las siete chacras. La forma de saldar estos gastos era a través de notas de crédito abiertas por el propietario en casas comerciales. En esas notas eran apuntados todos los gastos efectuados por el chacarero, incluído los vales para sus peones. Luego, estos gastos eran contabilizados en el debe de cada chacra.

A través de los gastos apuntados para las tareas estacionales sabemos que en la chacra se contrataban trabajadores para juntar maíz, trillar trigo y avena, acarrear cereales, o conducir tropas de animales. Pero no podemos saber cuantos trabajadores se contrataban. 
Estos gastos no estarían completos si no agregásemos el consumo alimenticio de estos hombres en la época de cosecha, los gastos de mantenimiento que implicaban las máquinas agrícolas (composturas, piezas de repuesto, herramientas, consumo de aceite) y la compra de aquellos artículos necesarios para la producción (hilo, lonas, etc.).

La carne, que representa la parte principal de los gastos de consumo alimenticio, es de producción interna de la estancia. Pero ella era contabilizada como los otros productos que eran comprados fuera del establecimiento. EI consumo de carne vacuna era mayor en la época de cosecha en tanto la ovina lo era en la época de la esquila. En cuanto a los otros gastos, el más importante lo constituye el mantenimiento y la inversión en alambrados e instalaciones. Luego el hilo para coser las bolsas de cereal y el mantenimiento de las máquinas de trabajo.

Una vez presentada la estructura de gastos, cabe preguntarse sobre el volúmen y el valor de la producción de estas chacras.

CUADRO 7: Trilla y venta de trigo correspondiente a siete chacras de la explotación de Ramón Santamarina en 1890

\begin{tabular}{|c|c|c|c|c|}
\hline \multirow{2}{*}{ Chacra } & \multicolumn{2}{|c|}{ Trilla de trigo } & \multicolumn{2}{c|}{ Venta de Trigo } \\
\cline { 2 - 5 } & Kgs. & Pesos* & Kgs. & Pesos** \\
\hline 25 de marzo & 310.529 & 1863.17 & 292.447 & 23.395 .76 \\
\hline 31 de enero & 182.527 & 1095.16 & 160.300 & 10.376 .80 \\
\hline Germania & 215.463 & 1292.77 & 165.830 & 12.390 .63 \\
\hline Retiro & 175.371 & 1052.22 & 156.061 & 9.675 .78 \\
\hline Destino & 96.254 & 577.52 & 73.554 & 6.252 .09 \\
\hline Santa Rosa & 81.179 & 487.07 & 66.157 & 5.988 .23 \\
\hline La Unión & $\mathbf{1 4 4 . 3 2 3}$ & 865.93 & $\mathbf{1 4 1 . 3 5 7}$ & 8.764 .13 \\
\hline Total: & $\mathbf{1 . 2 0 5 . 6 4 6}$ & $\mathbf{7 . 2 3 3 . 8 4}$ & $\mathbf{1 . 0 5 5 . 7 0 6}$ & $\mathbf{7 6 . 8 4 3 . 4 2}$ \\
\hline
\end{tabular}

CUADRO 8: Trilla y venta de avena correspondiente a siete chacras de la explotación de Ramón Santamarina en 1890 (Valores en pesos)

\begin{tabular}{|c|c|c|c|c|}
\hline \multirow{2}{*}{ Chacra } & \multicolumn{2}{|c|}{ Trilla de avena } & \multicolumn{2}{c|}{ Venta de avena } \\
\cline { 2 - 5 } & Kgs. & Pesos* & Kgs. & Pesos** $^{* *}$ \\
\hline 25 de marzo & 8.568 & 51.40 & 6.697 & 267.88 \\
\hline 31 de enero & 7.425 & 44.55 & 7.425 & 297.00 \\
\hline Germania & 4.512 & 27.07 & 4.440 & 177.60 \\
\hline Retiro & 5.207 & 31.24 & 5.207 & 208.82 \\
\hline Destino & - & - & - & - \\
\hline Santa Rosa & - & - & - & - \\
\hline La Unión & - & - & - & - \\
\hline Total: & $\mathbf{2 5 . 7 1 2}$ & $\mathbf{1 5 4 . 2 6}$ & $\mathbf{2 3 . 7 6 9}$ & $\mathbf{9 5 1 . 3 0}$ \\
\hline
\end{tabular}

Fuente: ARSNotas:

* La trilla se pagaba $60 \mathrm{cts}$ cada $100 \mathrm{kgs}$.

** Las cotizaciones de venta fueron de $\$ 4.00$. 
La comparación de ambos cuadros permite ver que el trigo proporcionó mejores dividendos que la avena. Si bien ambos cereales tenían la misma estructura de gastos, las diferencias de cotizaciones en el mercado (la del trigo es siempre más alta que la de la avena) y la mayor demanda internacional del trigo, justificaban la preferencia por este cereal. La venta del cereal era contabilizada en el Haber de cada chacra y en el Debe de la casa central de la estancia. Luego ella procedía a su venta fuera de la estancia: la plaza mercantil de Buenos Aires y molinos locales.

Por lo que vimos en los balances generales (que no hemos presentado aquí), este fue el mejor año de producción cerealera para las estancias de Santamarina, pues para los dos años siguientes la producción de trigo comenzó a decrecer en beneficio de una agricultura pastoril para cría y engorde de ganado vacuno y ovino. Las cifras del cuadro 9 permiten observar la baja del monto de las cosechas a través de los totales de las trillas.

\section{CUADRO 9: Producción de Trigo y Avena de la explotación de Ramón Santamarina}

\begin{tabular}{|c|c|c|c|c|}
\hline \multirow{2}{*}{ Año } & \multicolumn{2}{|c|}{ Trilla de Trigo } & \multicolumn{2}{c|}{ Trilla de Avena } \\
\cline { 2 - 5 } & Kgs. & Pesos* & Kgs. & Pesos** \\
\hline 1890 & 1.205 .646 & 7.233 .84 & 25.712 & 154.26 \\
\hline 1891 & 918.071 & 6.386 .47 & 45.086 & 416.40 \\
\hline 1892 & 133.420 & 4.035 .10 & - & - \\
\hline
\end{tabular}

Fuente: ARS

Es necesario tener en cuenta que en 1890, año de crisis, la trilla se pagó a 60 cts. cada 100 kgs., en 1891,70 cts. y en 1892, $\$ 2.50$. No hay que olvidar que ya para estos años se hacen sentir los efectos de la crisis de 1890. La misma evolución experimentan las cotizaciones en el mercado: en 1890 la cotización del trigo osciló entre un mínimo de $\$ 6.20$ a un máximo de $\$ 10, \$ 11$ y $\$ 12$, en 1891 fue de $\$ 5$ a $\$ 10, \$ 12$ y $\$ 16$ y en 1892 , de $\$ 9$ a $\$ 16$. La avena cotizó entre $\$ 4$ y $\$ 7$ en $1890, \$ 4.50$ en 1891 y $\$ 6$ en 1892 . Las cotizaciones aumentaron lo suficiente como para que los productores, en condiciones de alta incertidumbre, aumentaran la producción de trigo y siguieran percibiendo ingresos seguros.

En proporción también aumentó la consiguiente estructura de gastos encareciendo el levantamiento de las cosechas. Entre estos gastos, la evolución que experimentaron los precios de los principales productos alimenticios, indis- 
pensables para el sostenimiento de la mano de obra, se convierte en algo interesante a tener en cuenta.

En líneas generales, se observa una permanente suba de los precios hasta 1892, que es cuando alcanzan su pico más alto, y a partir de alli comienzan a descender. Todos estos productos -a excepción de la carne, de producción interna y las galletas, elaboradas por las panaderías del pueblo-, eran traídos del interior y distribuídos desde Buenos Aires, por lo que a más de su encarecimiento natural por efecto de la crisis aumentaba su precio debido al pago del flete correspondiente. Es evidente que el producto considerado de lujo, y por ende el más caro, era el café, ya que provenía del exterior, por lo que a partir de 1891 se lo comienza a reemplazar por el té.

También aumenta el precio de las bolsas vacías, de $\$ 0.18$ y $\$ 0.20$ en 1890 pasan a costar $\$ 0.30$. Lo mismo el alquiler de carros, mientras en 1890 salía $\$ 4$ el día, en 1891 y 1892 aumenta a $\$ 5$ y $\$ 8$. Y finalmente, aumenta el costo de la mano de obra al encarecerse su reproducción debido al aumento del costo de vida.

Las cifras presentadas aquí muestran que el movimiento productivo y comercial de las chacras era contabilizado por la casa central de la estancia que era la que organizaba y comercializaba la producción.

En el Haber correspondiente a su cuenta, aparece contabilizada la distribución de herramientas, maquinaria, útiles, mano de obra, cereales y animales de las chacras. La casa central respondía con todo lo necesario y cada chacra debía sembrar lo que se le asignara.

"Se mandó a la chacra de Porvenir 20 bolsas de avena para semilla, se llevó la sembradora y se empezará mañana a sembrar avena.

Recibí de Lorenzo los útiles que se le entregaron para arar y sembrar la chacra Independiente que son un arado completo con aperos, 2 rejas, 2 cuchillas, 1 rastra, 40 bolsas de retorno y 1 bolsa=68 $\mathrm{K}$ trigo ruso sobrante (Libro de Trabajos 10.09.91. ARS)".

Esto demuestra que el equipamiento técnico de las chacras era una decisión de la Casa Central, no de los chacareros, que son simples ejecutores. La contabilidad central calcula, del punto de vista del propietario y no del chacarero, los materiales plazados en cada chacra o prestados a ella, los costos de producción y el valor de las ventas.

De esta manera, la administración central de la estancia distribuía las semillas según tipo y cantidad seleccionada. Después de la trilla y venta de trigo y 
avena del año 1890, era necesario preparar la siembra del año siguiente. El Libro de Trabajos Diarios de 1891 registra la siguiente distribución de semillas entre las diferentes chacras (véase cuadro 10).

Esto hace en total una media de $32.5 \mathrm{kgs}$. por hectárea pues cada chacra tuvo un porcentaje de distribución diferente. Las cantidades sembradas son particularmente bajas según los standares europeos. En 1919, según el artículo de un ingeniero agrónomo aparecido en la revista $\mathrm{El} \mathrm{Campo}^{14}$, la cantidad de trigo aconsejable para sembrar a máquina era de 70 kilos por hectárea. El doble de lo que se apuntara 28 años atrás. A título de comparación, en la Europa clásica era corriente sembrar de 150 a $200 \mathrm{kgs}$. de trigo por hectárea. El argumento era que el exceso de semillas atentaba contra el buen desarrollo de las plantas y por ende contra su rinde. Es por ello que hay que tener en cuenta las diferencias en las semillas.

CUADRO 10: Distribución de semillas de trigo en las chacras de Ramón Santamarina 1891

\begin{tabular}{|c|c|c|c|c|}
\hline Chacra* & Chacarero & \multicolumn{2}{|c|}{ Trigo } & Superficie en \\
\hline & & Bolsas & Kgs. & Hectáreas \\
\hline Germania & Federico Hect & 43 & 2.653 & 214 \\
\hline Porvenir & Tristan Stub & 134 & 8.993 & 186 \\
\hline La Unión & Pablo Laborda & 74 & 4.426 & 185 \\
\hline República & Carlos Fucks & 62 & 6.173 & 152 \\
\hline Galicia & Camilo Hermida & 62 & 3.940 & 88 \\
\hline Santa Rosa & Justo Silva & 22 & 1.550 & 54 \\
\hline Destino & José Azcue & 2 & 116 & 51 \\
\hline Sol de Mayo & Bautista Gianolli & 24 & 1.549 & 41 \\
\hline Independiente** & Lorenzo & 25 & 1.536 & 13 \\
\hline Total: & & $\mathbf{4 4 8}$ & $\mathbf{3 0 . 9 3 6}$ & $\mathbf{9 8 4}$ \\
\hline
\end{tabular}

Fuente: ARS

Notas:

* También se envió trigo a la estancia San Ramón de la Tinta (Juárez), en total 162 bolsas con 10.451 kgs.

** La chacra Independiente sembró además 29 bolsas de avena lo que hace un total de $1.301 \mathrm{kgs}$ y Ta chacra Porvenir sembró 26 bolsas con $1.277 \mathrm{kgs}$.

Las semillas eran compradas por la estancia a los molinos del lugar y luego distribuídas y contabilizadas en el Debe de cada chacra. Junto a ellas se entregaban arados, aperos, máquinas sembradoras y sulfato de cobre para curar las semillas. Las chacras retornaban luego las bolsas vacías. En 1891, la estancia compró al Molino Viejo, propiedad de Pablo Christiansen en Tandil, bolsas de cereal a $\$ 10$.

Como vimos páginas arriba, la producción de trigo comenzó a decrecer en

14-El Campo, Año III, No 30(1919).

- Instituto de Historia Regional - Facultad de Ciencias Humanas - Universidad Nacional de La Pampa - 
provecho de una producción agrícola de tipo pastoril. Las chacras producían, además, maíz para gallinas, chanchos y pollitos, avena y cebada para alimento de los animales (carneritos y novillos), alfalfa para los toros y afrecho que se compraba fuera de la estancia. Pero algunas chacras no produjeron maíz lo cual no quita que luego tuvieran que habérselo comprado a otras chacras para contar con alimento para los animales.

\section{Puestos ganaderos}

La producción agrícola no fue la única actividad desarrollada en las estancias de Santamarina. La ganadería constituía la otra actividad pivote de su empresa.

Se daba la concertación de ciertos tipos de contratos que, según fuera la forma de pago concertada, podían ser de tercianería, cuarteanería, invernada y mensual.

En general, se trata de contratos de aparcería, por el cual, el propietario entregaba un pedazo de tierra -el puesto- con una equis cantidad de ovejas $y$ luego se encargaba de su comercialización; el puestero en tanto, se comprometía al cuidado de las ovejas y percibiría la parte (la mitad, el tercio o el cuarto según el contrato) de los aumentos que hubiere de los animales que vender.

Aquí precisamente aparecen algunas diferencias, pues según el contrato, podía tratarse de un puestero a sueldo, el mensual (que cada mes recibía su salario); puesteros a interés con capital (es el que teniendo un pequeño capital no alcanza a arrendar una fracción de campo, y por lo tanto, decide entrar en sociedad con algún estanciero que le dé un puesto y le iguale el capital cuidando ellos las ovejas. Si bien el contrato, según Daireaux (1887:98), se hacía a medias, lo común era hacerlo al tercio: el puestero aportaba la tercera parte de las ovejas y el estanciero, las dos terceras partes, dividiéndose luego las utilidades en la misma proporción); y puesteros a interés sin capital (son los que buscan ovejas para cuidar a interés y no a sueldo. En este sentido, el interés puede ser variable: la cuarta parte de los productos, el tercio de los aumentos y la cuarta parte de la lana).

Estos contratos están evidenciando la asociación entre un socio capitalista, que aportaba la tierra y el capital, y un socio trabajador, que aportaba su trabajo y algunas veces parte del capital, percibiendo por el mismo el correspondiente porcentaje de la venta de los productos.

En el archivo de Santamarina encontramos para los años 1893, 1894 y 1895 
un registro de los puestos existentes en sus propiedades con la indicación de su correspondiente denominación, nombre y apellido del puestero y tipo de contrato con el que figuraba. En el cuadro 11 hemos indicado el número total de puestos destinados a la producción ovina y el número y tipo de contratos para los años mencionados.

CUADRO 11: Contratos de producción ovina en las estancias de Santamarina

\begin{tabular}{|c|c|c|c|c|}
\hline Tipo de contrato & $\mathbf{1 8 9 2 / 9 3}$ & $\mathbf{1 8 9 3 / 9 4}$ & $\mathbf{1 8 9 4 / 9 5}$ & $\begin{array}{c}\text { Total } \\
\text { Contratos }\end{array}$ \\
\hline Terciería & 14 & 8 & 11 & 33 \\
\hline Invernada* $_{\text {Cuarteanería }}^{11}$ & 4 & 11 & 4 & 26 \\
\hline Mensual & 1 & 6 & 11 & 21 \\
\hline Sin datos & 2 & - & 10 & 11 \\
\hline Total Puestos & $\mathbf{3 2}$ & 5 & 2 & 9 \\
\hline
\end{tabular}

Nota: * Invernada significa engorde del ganado

Como se puede observar, en los totales se vislumbra una preponderancia del sistema a porcentaje (terciería, cuarteanería e invernada ${ }^{15}$ ) en relación al sistema a sueldo, pero si hacemos un análisis para cada año, veremos que el sistema mensual adquiere una gran importancia en 1895, en particular, en relación al sistema de invernada, en franco descenso. Este fenómeno se explica, como lo indica Daireaux (1887:97), por el hecho de que la forma más barata de hacer cuidar una majada era con mensuales, ya que éste "sabe que, cuide bien o cuide mal, cada mes recibirá su sueldo". Pero es necesario tener en cuenta también que para fines de siglo la invernada de bovinos comienza a tener mayor importancia, preferencia sin duda ligada, por un lado, al menor trabajo que los vacunos implicaban en relación al ovino -que inicia ya su franca emigración hacia el sur-,y por el otro, a la buena cotización que estaban teniendo los animales en el mercado. Para finales del siglo XIX, comienzan a observarse ciertas modificaciones productivas que se expresaron en un crecimiento de la producción bovina orientada a la exportación de carne congelada y animales en pie, conforme a las nuevas tendencias de consumo del mercado internacional.

Los datos aportan además del capital inicial, consistente en una equis cantidad de ovejas más un determinado número de carneros para el mejoramiento de las majadas, las correspondientes liquidaciones anuales de capital con sus respectivos aumentos. En ellas se especifica la producción de lana, cueros y animales, detallando precio por unidad y monto total de la operación. Del total

15-Debemos aclarar que la invernada también podía ser a sueldo.

- Instituto de Historia Regional - Facultad de Ciencias Humanas - Universidad Nacional de La Pampa - 
de la producción, se deducen los gastos correspondientes al alquiler de los carneros para el mejoramiento de las majadas y los gastos de esquila, del saldo obtenido, el propietario deduce el interés que le corresponde al puestero por contrato (la mitad, el tercio o el cuarto), y de ésa parte se le descuentan los gastos en concepto de alquiler del campo, baño de los animales y suministros varios, quedando de ésa manera el ingreso neto que le corresponde al puestero.

La cantidad de animales que se pueden destinar a un puesto depende fundamentalmente de la extensión y calidad del campo. Lo común es encontrar majadas de 1500 a 2000 animales en puestos de 100 a 150 hectáreas con sus correspondientes divisiones en potreros para separar y tener las varias clases de animales que forman el rebaño: la caponada, los borregos, las ovejas preñadas, etc.. Los contratos del cuadro 11 muestran una media de 1839 ovejas por puesto para el caso de los cuarteaneros, 1312 para los tercianeros y 1222 para los mensuales, en menor proporción siguen los invernadores con un promedio de 589 ovejas por puesto ${ }^{16}$. Por qué estas diferencias? Cómo explicar la relación entre cantidad de cabezas y tipo de contrato a firmar? Como dijéramos párrafos arriba, estas diferencias dependían del arreglo que se estableciera entre el propietario y el puestero y las condiciones y estado del campo y de los mercados.

Las liquidaciones eran realizadas por la administración central de manera detallada y prolija. Por ellas sabemos que el propietario, Santamarina, aportaba la tierra -por la cual muchas veces, según el contrato, cobraba un alquiler-, y el capital inicial (animales y la apertura de una cuenta corriente en la estancia ${ }^{17}$ ). En contrapartida, las obligaciones del puestero consistían en estacionar la majada, bañar las ovejas, sacar y cuidar los cueros y realizar la esquila, tareas para las cuales podía contratar la mano de obra necesaria.

Los gastos que demandaran dichas tareas así como los insumos necesarios, eran cubiertos por el propietario y al final del contrato eran descontados al puestero de la parte del producto que le correspondiera.

A pesar de que una majada no dá un producto fijo, sin embargo cuando las circunstancias lo permiten -el buen cuidado, el ciclo natural y las condiciones del mercado- es una actividad altamente rentable.

En el juego contable, la producción era adquirida por el propietario, sin

16- Debemos tener en cuenta que si bien los invernadores tienen majadas mas chicas (de 195 a 1424), $\sin$ embargo necesitan mas campo para invernar todos los animales destinados al matadero (Daireaux, 1887:141).

17- La apertura de esta cuenta corriente -que figurará como una cuenta especial en el Libro Mayor- tiene como finalidad el control de todos los gastos, en bienes de consumo, de trabajo y de capital, que efectuara el puestero. Estos gastos eran luego apuntados en sus liquidaciones anuales. 
intermediarios, quien basado en las cotizaciones del mercado, tasaba la lana, los cueros y los animales al puestero, deduciendo del ingreso total, los gastos respectivos y la parte del interés correspondiente. Esta producción era luego vendida en Buenos Aires.

Si tomamos un grupo de doce puestos (9 con contratos de terciería y 3 de cuarteanería ${ }^{18}$ ), para los cuales poseemos información completa para las liquidaciones de 1893/94 y 1894/95, veremos los siguientes resultados en el cuadro 12.

\section{CUADRO 12: Doce puestos de las estancias de Ramón Santamarina en Tandil}

\begin{tabular}{|c|c|c|c|c|c|c|}
\hline & \multicolumn{3}{|c|}{$1893 / 94$} & \multicolumn{3}{|c|}{$1894 / 95$} \\
\hline Puesto & $\begin{array}{l}\text { Capital } \\
\text { Inicial }\end{array}$ & Capital & Aumentos & $\begin{array}{l}\text { Capital } \\
\text { Inicial }\end{array}$ & Capital & Aumentos \\
\hline \multicolumn{7}{|c|}{ Contratos al Tercio } \\
\hline La Unión & $1672 / 10$ & 1702 & 30 & $1814 / 10$ & 1684 & -130 \\
\hline La Esperanza & $1177 / 9$ & 1300 & 123 & $1310 / 9$ & 1306 & -4 \\
\hline La Germania & $1600 / 10$ & 1656 & 56 & $2283 / 10$ & 1535 & -748 \\
\hline 12 de enero & $1001 / 10$ & 1421 & 420 & $1471 / 9$ & 2197 & 726 \\
\hline Santa Rosa & $1447 / 9$ & 1479 & 32 & $1567 / 10$ & 1627 & 60 \\
\hline El Lucero & $965 / 14$ & 1300 & 335 & $1352 / 10$ & - & - \\
\hline Los Leones & $931 / 14$ & 1307 & 376 & $1299 / 9$ & 1540 & 241 \\
\hline La Gloria & $1390 / 9$ & 1390 & - & $1190 / 9$ & 1400 & 210 \\
\hline El Cristiano & $1047 / 5$ & 1047 & - & $884 / 7$ & 1200 & 316 \\
\hline \multicolumn{7}{|c|}{ Contrato al Cuarto : } \\
\hline La Elvira & $1670 / 16$ & 1974 & 304 & $2372 / 14$ & 2000 & 372 \\
\hline La Josefina & $1360 / 10$ & 1550 & 190 & $1649 / 9$ & 1582 & 67 \\
\hline Segui et Destino & $3561 / 20$ & 3419 & -142 & $4287 / 17$ & 2317 & -1970 \\
\hline
\end{tabular}

Fuente: ARS

Notas: Los puesteros y el tipo de contrato fueron los mismos entre un año y otro en los siguientes casos: La Unión; P. Laborda; Esperanza: B.Gianolli; La Germania: J. Igorene; 12 de enero: I. Coria; Santa Rosa: T. Silva; La Elvira: M. Cabezas; El Lucero: M. Orcastegui; La Josefina: A. Navarro; Segui y Destino: J. Azcue; La Gloria: B. Espele y El Cristiano: C. Castro. La excepción lo constituye el puesto Los Leones que en 1893/94 estuvo a cargo de M. Olázabal con un contrato al Tercio y en 1894/95 estuvo a cargo de J. Guide con un contrato al cuarto.

¿Qué se observa? En primer lugar, que no siempre la cantidad de padres reproductores alquilados está en función directa al tamaño de la majada. En segundo lugar, que en algunas majadas hubo aumentos considerables, en otras no tanto y en otras por el contrario, hubo disminución en lugar de aumento. Las

18- Los puesteros pueden permanecer en el mismo puesto y con el mismo tipo de contrato durante los años que permanezcan en el establecimiento. Pero la combinatoria de situaciones puede ser múltiple, esto es que: un puestero puede permanecer por algunos años en el mismo puesto pero cambiando de contrato o conservar el mismo contrato pero cambiando de puesto o puede cambiar de contrato y de puesto. También puede darse el caso de que un puestero posea más de un puesto con distintos contratos o con el mismo. 
causas de que se produjera tanto uno como otro fenómeno pueden deberse a una multiplicidad de riesgos naturales y/o negligencia personal. Lo que sí es seguro es que ésta última no fue causa suficiente para que a ese puestero no se le renovara el contrato al año siguiente. Véase sino el caso del puestero josé Azcue (puesto Seguí y Destino). Durante dos años seguidos su capital tuvo disminuciones importantes en lugar de aumentos. Pero si tenemos en cuenta, por lo que se vió a través de las liquidaciones presentadas, que el puestero debía hacerse cargo de todos los gastos de producción, vemos por que sí los contratos eran renovados.

Si bien la producción de lana descendió en 1894/95, los ingresos en función de este producto aumentaron. La diferencia puede deberse a los cambios de cotización, en tanto la lana madre cotizó en 1893/94 a un promedio de $\$ 0.73$ y la lana borrega a $\$ 0.83$, en $1894 / 95$ el promedio general fue de $\$ 0.72$. También bajó la producción de animales para consumo y de cueros grandes, en tanto que los cueros chicos y los capones experimentaron un alza considerable. Las cotizaciones en este sentido vienen nuevamente en nuestra ayuda. En tanto los cueros grandes sufren una profunda baja que va de un promedio de $\$ 1.30$ en $1893 / 94$ a $\$ 0.90$ en $1894 / 95$, los cueros chicos sufren una baja más pronunciada aunque se compensa evidentemente con un aumento de la producción: el promedio va de $\$ 3.00$ en $1893 / 94$ a $\$ 0.22$ en 1894/95. En cuanto a los animales para consumo mantienen la misma cotización de $\$ 2.00$ cada uno para uno y otro año, en tanto los capones oscilan entre $\$ 4.60$ a $\$ 7.00$ en $1893 / 94$ y de $\$ 5.25$ a $\$ 9.10$ en $1894 / 95$.

- CUADRO 13: Producción e ingresos para doce puestos de las estancias de Santamarina

\begin{tabular}{|l|c|c|c|c|}
\hline \multirow{2}{*}{$\begin{array}{c}\text { Producción } \\
\text { de: }\end{array}$} & \multicolumn{2}{|c|}{ 1893/94 } & \multicolumn{2}{c|}{ 1894/95 } \\
\cline { 2 - 5 } & Unidades & Pesos & Unidades & Pesos \\
\hline Lana (en Kgs.) & 54.077 & 41.154 .84 & 5.317 & 48.292 .82 \\
\hline Animales & 5.836 & 11.782 .00 & 1.626 & 10.648 .00 \\
\hline Cueros Grandes & 1.844 & 2.381 .86 & 2.055 & 1.463 .40 \\
\hline Cueros Chicos & 392 & 628.36 & 1.031 & 432.86 \\
\hline Capones & 351 & 2.075 & & 6.529 .25 \\
\hline Totales: & & $\mathbf{5 8 . 0 2 2 . 4 6}$ & & $\mathbf{6 7 . 3 6 6 . 3 3}$ \\
\hline
\end{tabular}

Fuente: ARS

¿Cuánto significó esta producción en ingresos netos para el propietario, Santamarina, y sus puesteros? Siguiendo con la selección de los doce puestos, pudimos extraer los siguientes totales: 
CUADRO 14: Gastos e ingresos de doce puestos de las estancias de Santamarina

\begin{tabular}{|c|c|c|}
\hline \multirow{2}{*}{ Detalle } & $1893 / 94$ & $1894 / 95$ \\
\hline & Pesos & Pesos \\
\hline $\begin{array}{c}\text { Total de la Producción (lana, cueros y } \\
\text { animales) }\end{array}$ & 58.022 .46 & 67.366 .33 \\
\hline $\begin{array}{l}\text { Gastos de producción (en concepto de } \\
\text { alquiler de carneros y esquila*) }\end{array}$ & 6.104 .22 & 7.214 .74 \\
\hline $\begin{array}{l}\text { Intereses de puesteros por tercios y } \\
\text { cuartos }\end{array}$ & 15.641 .12 & 17.570 .64 \\
\hline $\begin{array}{l}\text { Gastos deducidos a los puesteros } \\
\text { (alquiler e insumos de campo*) }\end{array}$ & 2.325 .97 & 3.789 .81 \\
\hline
\end{tabular}

Fuente: ARS

Nota: *Debemos aclarar que los precios por unidad, como aparece detallado en las liquidaciones presentadas, se mantuvieron en estos años sin variación.

El total del capital inicial (ovejas más carneros) en 1893/94 fue de $17.821+135$ lo que implica un promedio de 1.485 ovejas mas 11 carneros por puesto y en 1894/95 el capital ascendió a $21.496+123$, dando un promedio de 1.791 ovejas más 10 carneros. Esto significó para la explotación un total en concepto de gastos de producción e intereses correspondientes a tercios y cuartos de puesteros de $\$ 21.745 .34$ para $1893 / 94$ y de $\$ 24.785 .38$ para $1894 / 95$ lo que restado al total de la producción da un ingreso para Santamarina de $\$ 36.277 .12$ en $1893 / 94$ y de $\$ 42.580 .95$ en $1894 / 95$. Esto hace un promedio de $\$ 3.023 .09$ por puestero para $1893 / 94$ y $\$ 3.548 .41$ para $1894 / 95$. Quizás las cifras en sí mismas no nos digan nada, pero sí nos dicen las relaciones de ingresos entre estanciero y puestero, pues el promedio de los intereses netos que les correspondieron a los puesteros por el cuarto o el tercio anual fue de $\$ 1.109 .59$ para $1893 / 94$ y $\$ 1.148 .40$ para $1894 / 95$. Esto hace una diferencia de $\$ 1.913 .50$ por cada puestero a favor de Santamarina en $1893 / 94$ y de $\$ 2.400 .01$ en $1894 / 95$.

\section{Conclusiones}

El patrimonio de Ramón Santamarina fue fundamentalmente un patrimonio fundiario. Sus estancias, diseminadas en varios partidos de la provincia de 
Buenos Aires, estuvieron dedicadas a una producción mixta orientada a la venta de productos agrícolas y al consumo de algunos de esos productos. Sobre esta base, las propiedades, y sobre todo las grandes y numerosas propiedades, como las de Ramón Santamarina, fueron divididas en un sinnúmero de pequeñas unidades llamadas chacras y puestos. Las chacras estuvieron destinadas al cultivo de cereales y los puestos destinados a la ganadería ovina. A esto hay que agregar la subdivision en cuadros y potreros de la unidad central de la estancia destinados a una producción mixta agrícola-ganadera.

Santamarina comenzó a adquirir tierras después de 23 años de su llegada a la Argentina y hasta su muerte, en 1904, no dejó de observar una política permanente de inversión en tierras continuada por sus hijos a través de la sociedad comercial Santamarina é hijos. Pero no sólo eso, esa política inversionista no sólo se orientó a acrecentar el patrimonio sino a hacerlo rentable capitalizando sus propiedades.

La organización de su empresa indica una diversificación/complementación productiva (explotación directa de la unidad central de la estancia agrícola-ganadera y concertación de contratos para chacras-agrícolas y puestos-ganaderos) que le ha permitido hacerla rentable.

Para hacer funcionar esta estructura productiva (recordemos que estos chacareros y puesteros sólo se hacían cargo de la producción, pues la comercialización de la misma corría por cuenta del propietario), era necesario observar una diversificada inversión. Esta se hizo de forma escalonada: dependiendo, en primer lugar, de cómo se fuera organizando la unidad de producción y, en segundo lugar, de las orientaciones productivas que se decidieran en función de las capacidades y fluctuaciones del mercado.

La oferta de tierras y el acceso al capital permitieron la acumulación por parte de algunos hombres. Y tengamos en cuenta que la tierra por sí misma no vale nada sino por el capital invertido. Por lo tanto, una cosa es el acceso a la propiedad de la tierra y otra el acceso a su explotación. El acceso a la propiedad marca una diferenciación entre propietarios y no propietarios. Pero ambos, de todas maneras, tienen la posibilidad de acceder a la explotación bajo diferentes formas de locación, o como mano de obra.

Los objetivos y finalidades de propietarios y productores fueron muy diferentes. Mientras el propietario buscaba rentabilisar su empresa, los no propietarios buscaban independizarse o fortalecerse como pequeños productores (según las posibilidades que ofrecieran los mercados). 


\section{Referencias bibliográficas}

*CARRETERO (A) 1970 "Contribución al conocimiento de la propiedad rural en la provincia de Buenos Aires para 1830" en: Boletín del Instituto de Historia Argentino-Americana, t.XIII, $\mathrm{N}^{\circ} 22$, Buenos Aires, Instituto de Historia Argentino-Americana, Dr. E. Ravignani, UBA.

*DAIREAUX (G) 1908 "L'estance argentine" en: République Argentine. Recensement agricole national. L'élevage et l'agriculture en 1908, Tome III.

*DAIREAUX (G) 1887 La cría del ganado en la estancia moderna, Buenos Aires, Agro.

*DELPECH (E) 1944 Una vida en la gran Argentina, relatos desde 1869 hasta 1944, Buenos Aires, Peuser.

*EL CAMPO 1918 Revista Ilustrada de agricultura, ganadería, industrias derivadas e informaciones generales, Buenos Aires, Años I (1917) a XII (1928). *GARAVAGLIA (J.C.) 1994 "La agricultura del trigo en las "estancias" de la campaña bonaerense: tecnología y empresas productivas (1750-1815)" en: R. Mandrini y A. Reguera (comps.) Huellas en la tierra, Tandil, IEHS.

*GARAVAGLIA (J.C.) 1993 "Los labradores de San Isidro (siglos XVIIr y XIX)" en: Desarrollo Económico, vol. 32, $\mathrm{N}^{\circ} 128$, Buenos Aires, IDES.

*GARAVAGLIA (J.C.) 1989 "Ecosistemas y tecnología agraria: elementos para una historia social de los ecosistemas agrarios rioplatenses (1700-1830)" en: Desarrollo Económico, vol. 28, No 112, Buenos Aires, IDES.

"GARAVAGLIA (J.C.) 1987 "Existieron los gauchos?" en: ANUARIO IEHS, № 2, Tandil, IEHS.

*GELMAN (J) 1992 "Producción campesina y estancias en el Río de la Plata colonial. La región de Colonia a fines del siglo XVIII"en: Boletín del Instituto de Historia Argentina y Americana, Dr. E. Ravignani, $N^{\circ} 6$, Buenos Aires, Instituto de Historia Argentina y Americana, Dr. E. Ravignani.

*GELMAN (J) 1989 "Una región y una chacra en la campaña rioplatense: las condiciones de la producción triguera a fines de la época colonial" en: Desarrollo Económico, vol.28, № 112, Buenos Aires, IDES.

*GUTIERREZ (B) 1947 "Los primeros estancieros" en: Anales de la Sociedad Rural Argentina, vol. LXXXI, No 10.

*HALPERIN DONGHI (T) 1992 "Clase terrateniente y poder político en Buenos Aires (1820-1930)" en: Cuadernos de Historia Regional, No 15, Luján, Universidad Nacional de Luján.

*REGUERA (A): 1999a "Familia, formación de patrimonios y transmisión de la 
tierra en Tandil (1840-1930)" en: J.C.Garavaglia, J.Gelman y B.Zeberio (comps.): Expansión capitalista y transformaciones regionales. Relaciones sociales y empresas agrarias en la Argentina del siglo XIX, Buenos Aires, IEHS-La Colmena.

*REGUERA (A): 1999b "Riesgo y saber. Control y organización productiva en las estancias pampeanas (1880-1930)" en: Anuario IEHS, N ${ }^{\circ} 14$, Tandil, IEHS.

*REGUERA (A): 1997 Estancias et entrepreneurs dans le cadre du développement de l'ecosysteme agraire de la région de la pampa (1880-1930). Etude de cas. Tesis de Doctorado, París, EHESS.

*REGUERA (A): 1993 "Arrendamientos y formas de acceso a la producción en el sur bonaerense: el caso de una estancia del Partido de Necochea, primera mitad del siglo XX"en: R.Mandrini y A.Reguera (comps.): Huellas en la tierra, Tandil, IEHS.

*SABATO (H) 1989 Capitalismo y ganadería en Buenos Aires. La fiebre del lanar, 1850-1890, Buenos Aires, Sudamericana.

\section{Fuentes}

*Archivo Privado Ramón Santamarina (Estancia Dos Hermanos, Partido de Tandil)

*Archivo Privado Miguel Cuevas (Estancia Napaleofú, Partido de Balcarce)

*Catálogo General de Mensuras, Archivo Histórico, Dirección de Geodesia de la Provincia de Buenos Aires

*Guía Rural del Partido de Tandil (1909)

*Guía de Propietarios Edelberg (1923)

* Guía de Propietarios de Campo por Cuarteles del Partido de Tandil (1928)

*Mapas catastrales $(1826,1864$ y 1890). 